\title{
GPS radio occultation with CHAMP and GRACE: A first look at a new and promising satellite configuration for global atmospheric sounding
}

\author{
J. Wickert, G. Beyerle, R. König, S. Heise, L. Grunwaldt, G. Michalak, Ch. Reigber, and T. Schmidt \\ GeoForschungsZentrum Potsdam (GFZ), Department 1, Geodesy and Remote Sensing, Telegrafenberg, 14473 \\ Potsdam, Germany
}

Received: 27 September 2004 - Revised: 17 December 2004 - Accepted: 10 January 2005 - Published: 30 March 2005

\begin{abstract}
CHAMP (CHAllenging Minisatellite Payload) and GRACE (Gravity Recovery And Climate Experiment) formed a satellite configuration for precise atmospheric sounding during the first activation of the GPS (Global Positioning System) radio occultation experiment aboard GRACE on 28 and 29 July 2004. 338 occultations were recorded aboard both satellites, providing globally distributed vertical profiles of refractivity, temperature and specific humidity. The combined set of CHAMP and GRACE profiles shows excellent agreement with meteorological analysis. Almost no refractivity bias is observed between 5 and $30 \mathrm{~km}$, the standard deviation is between 1 and $2 \%$ within this altitude interval. The GRACE satellite clock stability is significantly improved in comparison with CHAMP. This allows for the application of a zero difference technique for precise analysis of the GRACE occultation data.
\end{abstract}

Keywords. Meteorology and atmospheric dynamics (Instruments and techniques) - Radio science (Remote sensing; Instruments and techniques)

\section{Introduction}

Atmospheric scientists are looking forward to the promises that a GPS radio occultation multi-satellite constellation can offer. The unique combination of global coverage, high vertical resolution, long-term stability and all-weather capability of the radio occultation measurements are excellent characteristics for the improvement of numerical weather prediction and detection of climate trends (e.g. Kursinski et al., 1997). A first evidence of this potential was given by the pioneering U.S. American single satellite GPS/MET (GPS/METeorology) experiment (Rocken et al., 1997) between 1995 and 1997. Constellations, consisting of several satellites, will multiply this potential.

Correspondence to: J. Wickert

(jens.wickert@gfz-potsdam.de)
Successors of GPS/MET are the German CHAMP (Reigber et al., 2005) and the U.S. American/Argentinian SAC-C satellite (Satelite de Aplicaciones Cientificas-C). The measurements of CHAMP and SAC-C brought significant progress to the GPS occultation technique (e.g. Hajj et al., 2004; Kuo et al., 2004; Wickert et al., 2004b). CHAMP has provided almost continuous occultation data since February 2001. A Near-Real-Time (NRT) occultation analysis has been continuously demonstrated since February 2003. Currently, an average delay of $\sim 4 \mathrm{~h}$ between each measurement aboard CHAMP and the provision of analysis data (atmospheric excess phases) is achieved. Quality checked vertical profiles of refractivity, temperature and water vapor are derived with $\sim 2$ days of delay. First assimilation studies show a positive impact of CHAMP's occultation data to the global weather forecast (e.g. Healy et al., 2005). The continuously enlarging long-term data set allows for first climate change relevant investigations, for example, to study thermal variations in the tropopause region (e.g. Schmidt et al., 2004) or to generate global climatologies (Foelsche et al., 2005).

Up to now these studies are limited to data of only one single satellite, except for selected periods with SAC-C measurements. Future GPS occultation missions, as COSMIC (Constellation Observing System for Meteorology, Ionosphere and Climate) (Rocken et al., 2000), MetOp-GRAS (Meteorology Operational, Global Navigation Satellite Systems Radio Occultation Receiver for Atmospheric Sounding) (Larsen et al., 2005) or EQUARS (EQUatorial Atmosphere Research Satellite) (Takahashi et al., 2004) will not provide data before 2006. The activation of the GPS radio occultation experiment of the U.S. American/German GRACE mission (Tapley and Reigber, 2004; Dunn et al., 2003) opens the possibility to double the continuously and operational available globally distributed occultation measurements in relation to CHAMP before the upcoming missions.

In the following we present first results of combined CHAMP and GRACE occultation data analysis using the operational orbit and occultation processing system at GFZ. 


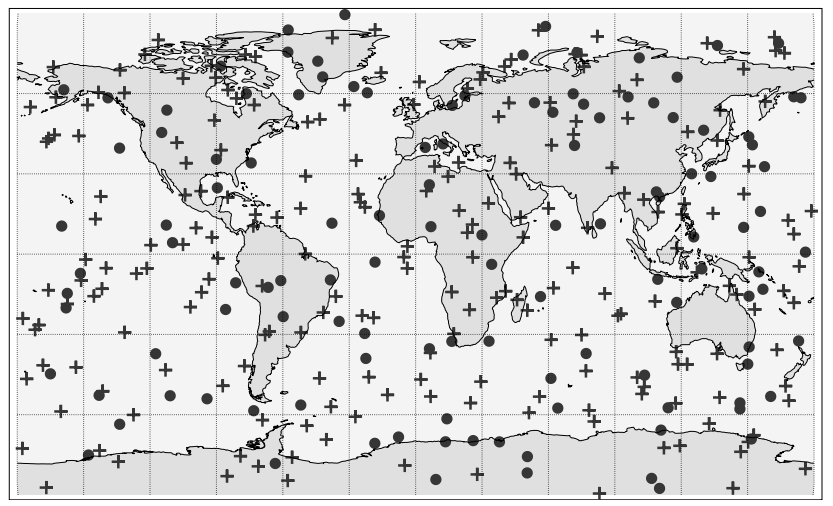

Fig. 1. Locations of the first occultations from GRACE (120 events, filled circles) and those from CHAMP (218 events, crosses) between 28 July (06:00 UTC) and 29 July (07:00), 2004.

\section{CHAMP and GRACE orbits}

CHAMP was launched into an almost circular near polar orbit (inclination $=87.2^{\circ}$ ) with an initial altitude of $454 \mathrm{~km}$ on 15 July 2000 . Two manoeuvres with orbit lifting $(\sim 20 \mathrm{~km})$ have been successfully carried out on 9 June and 10 December 2002. As of October 2004 the altitude is about $370 \mathrm{~km}$, a lifetime (mean altitude above $\sim 300 \mathrm{~km}$ ) until the end 2007 is expected. The GRACE satellites are in an almost circular, near-polar orbit (inclination $=89.0^{\circ}$ ) since 17 March 2002, with an initial altitude of $500 \mathrm{~km}$. The natural decay of the orbital altitude since launch is about $1.1 \mathrm{~km} /$ month, a lifetime longer than 2010 is feasible (Tapley and Reigber, 2004).

\section{First occultations from GRACE and CHAMP mea- surements}

The "BlackJack" GPS-Receiver (provided by Jet Propulsion Laboratory, JPL) aboard the GRACE-B satellite (aft-looking antenna to observe setting occultations) was activated for the first time in atmospheric sounding mode from 28 July, 06:00 UTC until 29 July at 07:00 UTC, 2004. 120 occultations (parallel tracking of occultation and reference satellite $\geq 20$ s) were recorded during this 25 -h interval. The CHAMP satellite provided 218 measurements during this period. Figure 1 shows the global distribution of the relevant CHAMP and GRACE occultation events. The number of the GRACE$B$ measurements was intentionally reduced during the test. This is mainly due to the reduction of the maximum viewing angle (angle between line of sight from the Low Earth Orbiter (LEO) to the occulting GPS satellite and the symmetry axis of the occultation antenna) to $40^{\circ}$ in relation to $60^{\circ}$ for CHAMP. Working in nominal mode, the same number of measurements as from CHAMP will be expected. We note that the symmetry axis of the CHAMP occultation antenna is tilted by $20^{\circ}$ to the Earth's surface compared to the anti-velocity direction. The GRACE antenna points at the anti-velocity direction.
The first CHAMP and GRACE-B measurements are complementary with respect to their local time (LT) coverage. On 28 July 2004, the longitude and local time of the CHAMP descending node (11:27 UTC) are $7.8^{\circ} \mathrm{E}$ and 11:58 LT, respectively. The corresponding values for the ascending node (12:13 UTC) are $176.2^{\circ} \mathrm{E}$ and 23:58 LT. The longitude and local time of the GRACE ascending node (11:49 UTC) are $116.1^{\circ} \mathrm{E}$ and 19:33 LT, respectively; for the descending node (12:36 UTC) $75.6^{\circ} \mathrm{W}$ and 07:33 LT, respectively. Due to the occultation geometry the local time of the ascending and descending nodes is about the same as the local time of the corresponding occultation events. The precise deviation depends on the location of the occultation and is limited by the maximum viewing angle.

The local time of the ascending and descending nodes of the GRACE orbit is changing with a rate of $\sim 1 \mathrm{~h} / 15$ days compared to $\sim 1 \mathrm{~h} / 11$ days for CHAMP.

\section{Data analysis}

\subsection{Infrastructure}

The operational occultation ground infrastructure from GFZ is used to provide and analyze both CHAMP and GRACE data. It consists of a polar and mid-latitude receiving station (Ny Ålesund, Spitsbergen, $79.0^{\circ} \mathrm{N}, 11.5^{\circ} \mathrm{E}$; and Neustrelitz, Germany, $53.1^{\circ} \mathrm{N}, 13.1^{\circ} \mathrm{E}$, operated by the German Aerospace Agency, DLR), a high rate and low latency fiducial network of globally distributed GPS ground stations (jointly operated with JPL), the automated satellite orbit and occultation processing systems and GFZ's data archive. The operational capability of these components allows for Near-Real-Time (NRT) occultation analysis, which has been continuously demonstrated with CHAMP since February 2003. Due to improvements in the ground station data handling for the precise orbit determination, the mean delay between each measurement aboard CHAMP and the provision of analysis results (atmospheric excess phase data) is reduced to currently $\sim 4 \mathrm{~h}$ (as of October 2004). A more detailed overview and relevant references are given by Wickert et al. (2004b).

\subsection{Retrieval}

A double difference method is applied to eliminate satellite clock errors within the current operational analysis of the occultation data from CHAMP (Wickert et al., 2004a) and GRACE. This technique makes the data analysis independent from the activation status of the Selective Availability (SA) mode of the GPS. Within this study we also applied space-based single and zero difference technique for the atmospheric excess phase calibration as described in more detail in Sect. 4.3.

Atmospheric bending angles are derived from the time derivative of the excess phase after appropriate filtering (Singular Value Decomposition fit (Press et al., 1996) encompassing 70 points of $50 \mathrm{~Hz}$ data). The ionospheric correction 
is performed by linear combination of the $\mathrm{L} 1$ and $\mathrm{L} 2$ bending angle profiles (Vorobev and Krasilnikova, 1994). To correct for the effect of lower troposphere multipath, the Full Spectrum Inversion (FSI) technique (Jensen et al., 2003), a wave optics based analysis method, is applied below $15 \mathrm{~km}$.

Vertical profiles of atmospheric refractivity are derived from the ionosphere corrected bending angle profiles by Abel inversion. For dry air, the density profiles are obtained from the relationship between density and refractivity. Pressure and temperature ("dry temperature") are obtained from the hydrostatic equation and the equation of state for an ideal gas. More details on the retrieval are given by Wickert et al. (2004b). The basics of the GPS radio occultation technique and the derivation of atmospheric parameters are described in detail, for example, by Kursinski et al. (1997).

The atmospheric refractivity, derived from GPS radio occultation measurements, is composed of a dry and wet contribution. Therefore, additional information is required to solve for this ambiguity and to derive vertical profiles of temperature and humidity in the mid and lower troposphere. We have used background information from operational meteorological analyses of the European Centre for Medium-Range Weather Forecasts (ECMWF) at the analyses' pressure levels to derive specific humidity profiles from the CHAMP and GRACE refractivities (Heise et al., submitted, 2005). ${ }^{1}$

\subsection{Use of satellite orbit and clock data}

The atmospheric excess phase of the occultation link is derived from precise phase observations $L$ aboard the LEO satellite. It can be written in units of meters as

$$
L=\rho+c(d t-d T)-d I+d A+\epsilon .
$$

The true range between transmitter and receiver, taking into account the signal travel time, is $\rho$. The velocity of light is $c$, and $d t$ and $d T$ are the transmitter and receiver clock errors, respectively. The phase delays, induced by the ionosphere and neutral atmosphere along the ray path, are indicated by $d I$ and $d A$. The residual error $\epsilon$ is composed of, for example, measurement noise, uncorrected multipath contribution and relativistic effects. The aim of the calibration process is to derive a time series of the atmospheric contribution $d A$, the atmospheric excess phase (see Sect. 4.2) during the occultation event.

The range contribution can be eliminated by using precise orbit information from the LEO (e.g. CHAMP or GRACE) and GPS satellites, the ionospheric contribution by forming a linear combination of the signals on both GPS carrier frequencies $(\mathrm{L} 1=1.57542 \mathrm{GHz}, \mathrm{L} 2=1.22760 \mathrm{GHz})$ or of the bending angles, derived from the two excess phases (Vorobev and Krasilnikova, 1994).

The clock contributions can be eliminated by the application of difference techniques to the GPS data analysis, for

\footnotetext{
${ }^{1}$ Global monitoring of tropospheric water vapor with GPS radio occultation aboard CHAMP, manuscript available: www.arxiv.org/physics/0502085
}

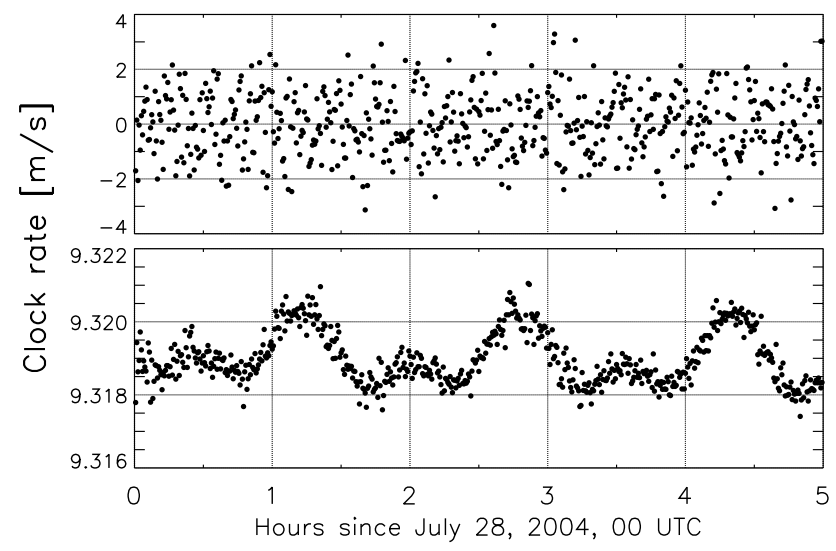

Fig. 2. Rate (or Drift) of the CHAMP (upper panel) and GRACE (lower panel) $30 \mathrm{~s}$-satellite clock solutions for 28 July 2004. The CHAMP drift are unstable in time, whereas the GRACE clock drift is very stable and can be modelled with sufficient accuracy. The periodic oscillations are due to effects of the specific and general theory of relativity.

example, the formation of a double difference,

$\Delta \Delta L=\left(L_{L O}-L_{L R}\right)-\left(L_{G O}-L_{G R}\right)$,

is formed from simultaneous LEO and ground station measurements of signals from the occulting and a second, referencing, GPS satellite during an occultation. The subscripts $L, O, R, G$ denote LEO, Occulting and Referencing GPS satellite and the Ground station, respectively. Corrections of relativistic and light time effects have to be taken into account (Hajj et al., 2002; Beyerle et al., submitted, 2005 $\mathrm{a}^{2}$ ). Differencing methods eliminate the clock errors, but introduce other errors by the auxiliary satellite links involved. These errors are, for example, uncalibrated atmospheric and ionospheric contributions and additional noise.

Due to the availability of more stable GPS clocks (Termination of the SA mode of the GPS on 2 May 2000) the application of the space-based single difference technique using 5-min GPS clock solutions became feasible and was demonstrated by Wickert et al. (2002) using CHAMP data.

To avoid the application of the space-based single difference method, and consequently the disturbing influence of the reference link $L_{L R}$ (introducing noise and ionosphere, see above), the satellite clock aboard the LEO has to be stable enough to be represented by the clock solutions. These data are provided as one result of the LEO orbit determination (König et al., 2005). Most important for the occultation analysis are stable clock drifts, rather than the knowledge of the absolute clock values themselves, because bending angles are derived from the time derivative of the atmospheric excess phase.

Figure 2 shows a comparison of the clock rates, derived from 30-s clock solutions from CHAMP and GRACE for

\footnotetext{
${ }^{2}$ GPS radio occultation with GRACE: Atmospheric profiling utilizing the zero difference technique, manuscript available: www.arxiv.org/physics/0409032
} 

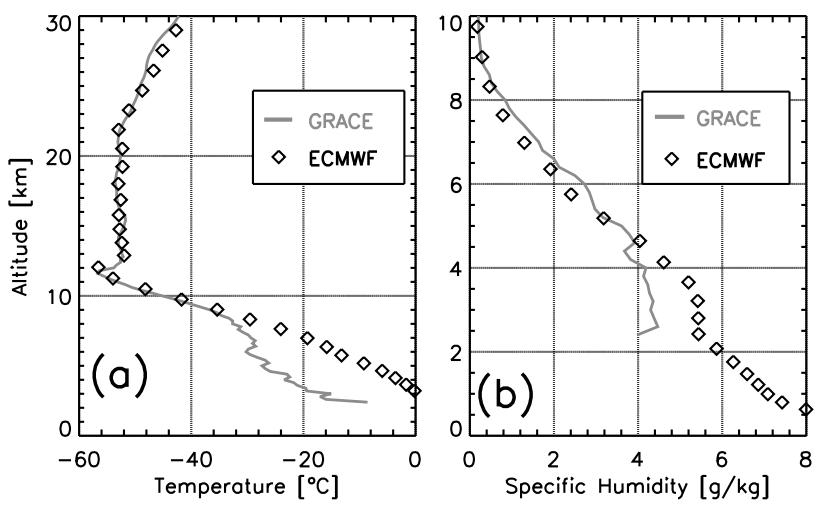

Fig. 3. Vertical profiles of (a) dry temperature and (b) specific humidity, derived from the first occultation measurement aboard GRACE, compared with corresponding ECMWF analysis $\left(55.31^{\circ} \mathrm{N}, 22.32^{\circ} \mathrm{E}\right), 28$ July $2004,06: 10$ UTC.
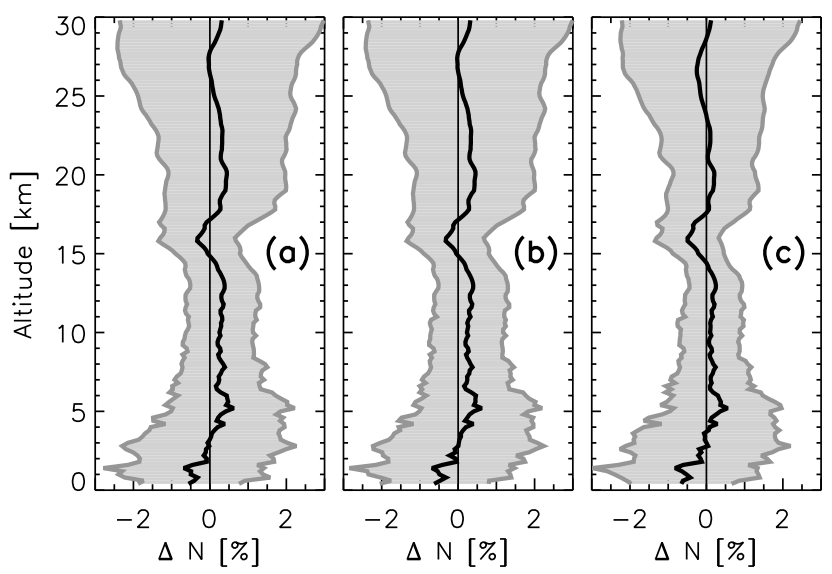

Fig. 4. Statistical comparison between 87 refractivity profiles, derived from GRACE measurements and 6-h ECWMF analyses during 28 and 29 July 2004. The differences (GRACE-ECMWF) are plotted for the profiles derived using (a) double differencing, (b) single differencing and (c) zero differencing.

a period on 28 July 2004 . Rates of $1 \mathrm{~mm} / \mathrm{s}$ are required to reach sub-Kelvin accuracies at heights of about $30 \mathrm{~km}$ (Wickert et al., 2002). The CHAMP clock shows nearly no drift, but the solutions cannot be used for precise clock correction; variations in the clock drift on the order of $\sim \mathrm{m} / \mathrm{s}$ are observed. This is due to periodic adjustments that are applied every second by the receiver processing and controlling system in order to meet a $1 \mu \mathrm{s}$ absolute time signal error imposed by the primary scientific instruments of the CHAMP mission. The GRACE clock solutions exhibit a large drift $(\sim 9.3 \mathrm{~m} / \mathrm{s})$, but this is very stable in time and can be modelled with sufficient accuracy. The periodic oscillations (about $1.5 \mathrm{~h}$ ) are due to relativistic effects. We've used a linear fit across a 5-min time window covering the according occultation to model the GRACE clock and to analyse the occultation data without difference techniques, i.e. zero differencing.
The feasibility of zero differencing was first shown by Beyerle et al., submitted, (2005a) $)^{3}$ using GRACE data, who give a detailed technical discussion of this method. These investigations and the corresponding results are completely independent from our study, since two separate software packages (an experimental and the operational processing software from GFZ) were used for the occultation data analysis.

\section{Results}

\subsection{First profile from GRACE}

The location of the first occultation measurement from GRACE $\left(55.31^{\circ} \mathrm{N}, 22.32^{\circ} \mathrm{E}\right)$ is not far from the geographical centre of Europe $\left(54.85^{\circ} \mathrm{N}, 25.32^{\circ} \mathrm{E}\right.$, nearby Vilnius, Lithuania). The retrieved profiles of dry temperature and specific humidity, and the corresponding ECMWF profiles are depicted in Fig. 3. The dry temperature profile matches well with the analysis. Below $8 \mathrm{~km}$, in the presence of water vapor, the dry temperature exhibits a cold bias in relation to the analysis temperature. This deviation is a measure for the water vapor content, itself shows good agreement with ECMWF, where larger deviations are observed below $4 \mathrm{~km}$. The FSI algorithm provides a criterion to cut-off the data at $2.4 \mathrm{~km}$ altitude without using auxiliary data for quality control. On a global average 28\% of the GRACE profiles can be derived down to the first kilometer above the Earth's surface.

\subsection{Comparison of GRACE profiles with ECMWF}

A set of 87 GRACE measurements is used to compare double, single and zero differencing results with ECMWF. This number is lower than the total number (120) of the available GRACE measurements and also lower than the number of the derived single and zero difference profiles (101), for which the calibration process (derivation of the atmospheric excess phase) was successful. To ensure the comparability of the results only those profiles were considered which could be analyzed by all three differencing techniques. This number is limited by the reduced number of 87 double difference profiles in relation to the 101 zero and single difference measurements due to reduced ground station availability for our study. In general, the application of the double difference method does not reduce the number of analyzed occultations, if full access to all available ground station data is ensured. But avoiding the direct use of GPS ground station data for the occultation processing is a clear advantage of the single and zero difference technique in relation to the standard double differencing, because of the simplification of processing systems and the entire avoidance of error contributions from the ground-to-satellite links (Wickert et al., 2002).

\footnotetext{
${ }^{3}$ GPS radio occultation with GRACE: Atmospheric profiling utilizing the zero difference technique (manuscript available: www.arxiv.org/physics/0409032)
} 
The vertical refractivity profiles are compared with ECMWF analyzes (resolution in longitude and latitude $0.5^{\circ}$, in 60 vertical pressure levels). The comparison is shown in Fig. 4. The results of the double and single difference set show no discernable differences. In contrast, the zero difference data show on average better agreement with ECMWF. The slight positive bias of about $0.3 \%$ in the GRACE data is not observed and the standard deviation is reduced from $\sim 0.9 \%$ to $\sim 0.7 \%$ at altitudes around $10 \mathrm{~km}$. A larger bias at $\sim 15 \mathrm{~km}$ (slightly below the northern summer tropical tropopause region) of $\sim 0.5 \%$ is observed. This enhanced negative bias is also observed within a larger set of CHAMP data (Wickert et al., 2005) at tropical latitudes over regions with strong convection and also over Antarctica. A detailed investigation is beyond the scope of this study. However, the following factors might contribute. First, a deviation from spherical symmetry of the refractivity distribution at tropical latitudes due to inhomogeneous water vapor distributions might cause a bias (Beyerle et al., submitted, 2005b). ${ }^{4}$ A similar explanation can be assumed for the bias at $\sim 15 \mathrm{~km}$ over Antarctica. Here, the formation of the Polar vortex during South Polar Winter (as for 28 and 29 July) can be a source for deviations from spherical symmetry. Second, lower accuracy of the meteorological analysis fields over the Tropics and Antarctica might contribute as well. Third, another source for deviations in the tropopause region was discussed first by Rocken et al. (1997) with GPS/MET measurements and is related to the different vertical resolution of the occultation measurements in relation to the analyses.

\subsection{Comparison of a combined CHAMP/GRACE data set with ECMWF}

The combined data set consists of 178 CHAMP and 101 GRACE measurements (279 in total). The data are analyzed using the single (CHAMP) and zero difference techniques (GRACE), as it can be assumed for future operational data analysis. Figure 5 shows good agreement with the meteorological analysis. Nearly no refractivity bias is observed between 5 and $30 \mathrm{~km}$. The standard deviation is between 1 and $2 \%$ within the entire altitude interval. This result is comparable to those of validation studies using only the data from CHAMP (Wickert et al., 2004b). Below $5 \mathrm{~km}$ a negative refractivity bias is observed. This is already known from the CHAMP measurements (e.g. Ao et al., 2003; Beyerle et al., 2003). Investigations related to different characteristics of the CHAMP and GRACE profiles will follow once a more extensive data set becomes available.

\footnotetext{
${ }^{4} \mathrm{An}$ analysis of refractivity biases detected in GPS radio occultation data: Results from simulation studies, aerological soundings and CHAMP satellite observations, manuscript available: www.arxiv.org/physics/0502052
}

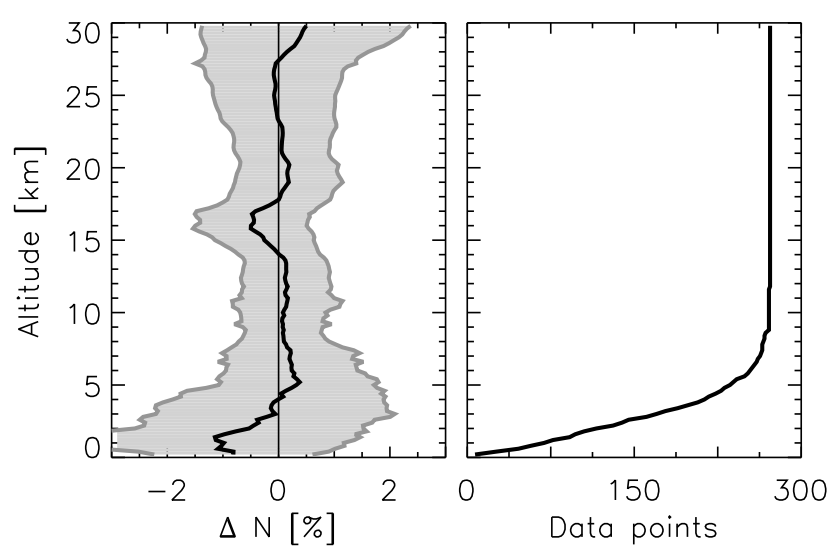

Fig. 5. Statistical comparison between 279 refractivity profiles, derived from CHAMP and GRACE measurements and 6-h ECWMF analyzes during 28 and 29 July 2004 (CHAMP/GRACE-ECMWF).

\section{Conclusions and outlook}

First results from parallel GPS radio occultation measurements aboard the CHAMP and GRACE satellites are presented. Data for a 25 -h period are available for our study. The data are analyzed using the automated occultation processing systems at GFZ to provide globally distributed vertical profiles of atmospheric refractivity, temperature and water vapor. A space-based single and zero difference techniques are applied for the analysis of the CHAMP and GRACE data, respectively. For GRACE we found a quality improvement of the refractivity profiles by avoiding double or single difference techniques. A common set of CHAMP and GRACE refractivity profiles is compared with meteorological analysis from ECMWF and shows similar quality compared to the CHAMP only measurements.

Our study has shown that new GPS occultation sensors could be used quite effortlessly to extend existing satellite configurations. The data can be analyzed using the existing ground infrastructure and processing systems. There is no need for an additional calibration effort, as, for example, for nadir-viewing radiometer missions. We regard this as an additional advantageous feature of the GPS occultation technique, which will help to build up powerful multi-satellite occultation configurations within the near future.

On the basis of these first results we anticipate that the continuous activation of GPS occultations aboard GRACE will significantly increase the number of globally distributed GPS-based atmospheric profiles of high quality. This will allow for more significant studies to improve global weather forecasts and to detect relevant climate change variations of the Earth's atmosphere.

Acknowledgements. The German Ministry of Education and Research (BMBF) supports the GRACE project within the GEOTECHNOLOGIEN geoscientific $\mathrm{R}+\mathrm{D}$ programme under grant 03F0326A. The German Weather Service provided ECMWF analysis data. We thank the complete CHAMP and GRACE team with the colleagues from GFZ and JPL for their work, which is the base 
for our investigations. We acknowledge the work of two anonymous reviewers and A. von Engeln for their critical reading of our manuscript.

Topical Editor O. Boucher thanks G. B. Larsen and another referee for their help in evaluating this paper.

\section{References}

Ao, C. O., Meehan, T. K., Hajj, G. A., Mannucci, A. J., and Beyerle, G.: Lower-Troposphere Refractivity Bias in GPS Occultation Retrievals, J. Geophys. Res., 108, doi:10.1029/2002JD003 216, 2003.

Beyerle, G., Wickert, J., Schmidt, T., and Reigber, C.: Atmospheric sounding by GNSS radio occultation: An analysis of the negative refractivity bias using CHAMP observations, J. Geophys. Res., doi:10.1029/2003JD003922, 2003.

Dunn, C., Bertiger, W., Bar-Sever, Y., Desai, S., Haines, B., Kuang, D., Franklin, G., Harris, I., Kruizinga, G., Meehan, T., Nandi, S., Nguyen, D., Rogstad, T., Thomas, J. B., Tien, J., Romans, L., Watkins, M., Wu, S.-C., Bettadpur, S., and Kim, J.: Instrument of GRACE - GPS Augments Gravity Measurements, GPS World, 1 February, 2003.

Foelsche, U., Kirchengast, G., Gobiet, A., Steiner, A., Löscher, A., Wickert, J., and Schmidt, T.: The CHAMPCLIM project: An overview, in Earth Observation with CHAMP: Results from Three Years in Orbit, edited by Reigber, C., Schwintzer, P., Lühr, H., and Wickert, J., 615-620, Springer Verlag, 2005.

Hajj, G. A., Kursinski, E. R., Romans, L. J., Bertiger, W. I., and Leroy, S. S.: A technical description of atmospheric sounding by GPS occultation, J. Atmos. Solar-Terr. Phys., 64, 451-469, 2002.

Hajj, G. A., Ao, C. O., Iijima, B. A., Kuang, D., Kursinski, E. R., Mannucci, A. J., Meehan, T. K., Romans, L. J., de la Torre Juarez, M., and Yunck, T. P.: CHAMP and SAC-C atmospheric occultation results and intercomparisons, J. Geophys. Res., D06109, doi:10.1029/2003JD003909, 2004.

Healy, S., Jupp, A., and Marquardt, C.: Forecast impact experiments with CHAMP GPS radio occultation measurements: Preliminary results, Geophys. Res. Lett., 32, L03804, doi:10.1029/2004GL020806, 2005.

Jensen, A. S., Lohmann, M., Benzon, H.-H., and Nielsen, A.: Full spectrum inversion of radio occultation signals, Radio Sci., 38, doi:10.1029/2002RS002763, 2003.

König, R., Michalak, G., Neumayer, K., Schmidt, R., Zhu, S., Meixner, H., and Reigber, C.: Recent developments in CHAMP orbit determination at GFZ, in Earth Observation with CHAMP: Results from Three Years in Orbit, edited by Reigber, C., Schwintzer, P., Lühr, H., and Wickert, J., Springer Verlag, 2005.

Kuo, Y.-H., Wee, T.-K., Sokolovskiy, S., Rocken, C., Schreiner, W., Hunt, D., and Anthes, R. A.: Inversion and Error Estimation of GPS Radio occultation Data, J. Meteorol. Soc. Jpn., 1B, 507531, 2004.

Kursinski, E. R., Hajj, G. A., Schofield, J. T., Linfield, R. P., and Hardy, K. R.: Observing Earth's atmosphere with radio occultation measurements using Global Positioning System, J. Geophys. Res., 19, 23 429-23 465, 1997.
Larsen, G., Lauritsen, K., Rubek, F., and Sørensen, M.: Processing of CHAMP Radio Occultation Data Using GRAS SAF Software, in Earth Observation with CHAMP: Results from Three Years in Orbit, edited by Reigber, C., Schwintzer, P., Lühr, H., and Wickert, J., 543-548, Springer Verlag, 2005.

Press, W. H., Teukolsky, S. A., Vetterling, W. T., and Flannery, B. P.: Numerical Recipes in Fortran 77, The Art of Scientfic Computing, Cambridge University Press, 1996.

Reigber, C., Schwintzer, P., Lühr, H., and Wickert, J.: Earth Observation with CHAMP: Results from Three Years in Orbit, Springer Verlag, 2005.

Rocken, C., Anthes, R., Exner, M., Hunt, D., Sokolovskiy, S., Ware, R., Gorbunov, M., Schreiner, W., Feng, D., Herman, B., Kuo, Y.H., and Zou, X.: Analysis and validation of GPS/MET data in the neutral atmosphere, J. Geophys. Res., 102, 29 849-29 866, 1997.

Rocken, C., Kuo, Y.-H., Schreiner, W., Hunt, D., Sokolovskiy, S., and McCormick, C.: COSMIC System description, Terrestrial, Atmospheric and Oceanic Sciences, 11, 21-52, 2000.

Schmidt, T., Wickert, J., Beyerle, G., and Reigber, C.: Tropical tropopause parameters derived from GPS radio occultation measurements with CHAMP, J. Geophys. Res., 109, D13105, 10.1029/2004JD004566, 2004.

Takahashi, H., Carvalho, H., Souza, P., Tsuda, T., Lowe, R., Taylor, M., Dallaqua, R., Abdu, M., Alarcon, M., and Bernhardt, W. G.: Scientific satellite EQUARS for remote sensing of the Equatorial atmosphere, 7th Latin-American Conference on Space Geophysics, Atibaia, April, 2004.

Tapley, B. and Reigber, C.: GRACE (Gravity Recovery and Climate Experiment), in McGraw-Hill Yearbook of Science \& Technology, 2004.

Vorobev, V. V. and Krasilnikova, T. G.: Estimation of the accuracy of the refractive index recovery from Doppler shift measurements at frequencies used in the NAVSTAR system, Phys. Atmos. Ocean, 29, 602-609, 1994.

Wickert, J., Beyerle, G., Hajj, G. A., Schwieger, V., and Reigber, C.: GPS radio occultation with CHAMP: Atmospheric profiling utilizing the space-based single difference technique, Geophys. Res. Lett., 29, doi:10.1029/2001GL013 982, 2002.

Wickert, J., Galas, R., Schmidt, T., Beyerle, G., Reigber, C., Förste, C., and Ramatschi, M.: Atmospheric sounding with CHAMP: GPS ground station data for occultation processing, Phys. Chem. Earth, 29, 267-275, 2004a.

Wickert, J., Schmidt, T., Beyerle, G., König, R., Reigber, C., and Jakowski, N.: The radio occultation experiment aboard CHAMP: Operational data processing and validation of atmospheric parameters, J. Meteorol. Soc. Jpn., 82, 381-395, 2004 b.

Wickert, J., Schmidt, T., Beyerle, G., Michalak, G., König, R., Heise, S., and Reigber, C.: GPS radio occultation with CHAMP and GRACE: Recent results, in Proc. OPAC-2 workshop, Graz September 2004, Kirchengast, G., Foelsche, U., and Steiner, A. K. (Eds.), Springer Verlag, 2005. 